\title{
ESTUDO SOBRE A DISCRIMINAÇÃO DE GÊNERO NA HISTÓRIA DA ESPANHA
}

\author{
STUDY ON GENDER DISCRIMINATION IN THE HISTORY OF SPAIN
}

Douglas Verbicaro Soares

Universidade Federal de Roraima, Boa Vista, RR, Brasil. E-mail: douglas_verbicaro@yahoo.com.br

DOI: http://dx.doi.org/10.31512/missioneira.v23i2.645 Recebido em: 26/09/2021 Aceito em: 27/12/2021

Resumo: Este estudo tem por finalidade demonstrar a situação das mulheres no mundo, em especial na realidade da Espanha, suas problemáticas e fatores responsáveis pela difícil tarefa da busca por um tratamento igualitário em relação aos homens. Trabalhar com o tema de direitos das mulheres representa uma importante iniciativa para a busca de melhores condiçóes para inclusão das mesmas não apenas no contexto espanhol, mas em diversas sociedades. A igualdade de condiçóes entre homens e mulheres é a base de um ideal feminista, assim como também um objetivo a se buscar para a efetivação de uma sociedade justa e harmônica entre os gêneros. Para a investigação foi pensada uma abordagem qualitativa dedutiva com pesquisa bibliográfica. $\mathrm{O}$ trabalho aponta a existência de obstáculos que perpetuam a desigualdade de gênero.

Palavras-chave: Dignidade. Proteçấo. Esforços. Problemas.

\begin{abstract}
This study aims to demonstrate the situation of women in the world, especially in the reality of Spain, their problems, and factors responsible for the difficult task of seeking equal treatment in relation to men. Working with the theme of women's rights represents an important initiative for the search for better conditions for their inclusion not only in the Spanish context, but in various societies. The equality of conditions between men and women is the basis of a feminist ideal, as well as an objective to be sought for the realization of a just and harmonious society between genders. For the research, a deductive qualitative approach with bibliographic research was designed. The paper points out the existence of obstacles that perpetuate gender inequality.
\end{abstract}

Keywords: Dignity. Protection. Efforts. Problems.

\section{Introduçáo}

estudo mostra uma análise sobre o gênero, violência e das experiências vividas pelas
mulheres, desde o Regime Totalitário do General Franco até a atualidade. Em este sentido, o breve ensaio parte se de um entendimento que: as mulheres, em meados dos anos 30 e nas décadas seguintes, eram reguladas por um forte ideal conservador em sociedade. No caso 
da Espanha, esse ideal impedia a liberdade feminina, sua participação efetiva como cidadã, pois suas ações acabavam limitadas à vida familiar, atribuições domésticas, numa esfera privada e submissa. Idéia essa encontrada nos discursos de Pillar Primo de Rivera em 1942, por exemplo: as mulheres não descobriam nada, que lhes faltava supostamente talento criador, talento esse reservado por Deus apenas aos varôes. ${ }^{1}$

As mulheres, naqueles tempos, não poderiam fazer nada mais que interpretar o que os homens faziam. Esse contexto demonstra a realidade do forte papel de excluir esse coletivo do Governo Totalitário de Franco, que impedia às mulheres de seguirem seus estudos nas universidades espanholas. Essa limitação se manteve por muitas décadas, o que refletia no quadro de estudantes das universidades, onde para cada mulher que era aceita, existia um percentual de seis homens em carreira. Não se esquecendo da separação clara nos cursos escolhidos, pois a mulheres se concentravam em cursos de magistério, estudos sanitários, farmácia, que se refletem ao ideal de cuidados, certa extensão de mãe cuidadora, assim como também, com cursos de filosofia e letras. $^{2}$

A discussão do tema do presente estudo está relacionada com os debates mais recentes sobre a violência de gênero, condutas sexistas e os róis atribuídos pela sociedade. Todo este temário está sendo visibilizado em diferentes universidades da Espanha, assim como na publicação de materiais científicos relacionados no país ibérico e, também, pelo mundo. Além disso, tem que ver com o movimento mais recente do feminismo, onde se apontam as reivindicaçóes de grupos vitimados que necessitam uma real sensibilização social para lograr a participação (cidadania) em direitos e deveres, sob proteção do Estado. ${ }^{3}$ É importante ressaltar que este tema se encontra na mira de muitos outros países, já que a violência de gênero está presente no âmbito internacional e quando ocorre, viola todos os princípios básicos do ser humano, prejudicando os direitos fundamentais e violando a dignidade humana.

Devido ao auxílio do movimento feminista, mudanças de paradigma foram implementados em favor da igualdade de trato entre homens e mulheres. Por último, mas não menos relevante: é um assunto tratado quase que diariamente nos meios de comunicaçáo, uma vez que, todos os dias são explicitados casos em que o coletivo de mulheres é vitimado por seus companheiros, familiares, amigos. Temário que se relaciona com as seguintes idéias: 1) vítimas submetidas e exploradas de diferentes maneiras. 2) situaçóes de denuncias, onde se busca evidenciar os abusos, crimes e reivindicar a igualdade de trato e o reconhecimento do ordenamento jurídico nacional em resolver os problemas (econômicos, políticos, culturais, religiosos, sexuais). 3) Momento da cidadania participativa - efetiva atuação, onde as pessoas (a sociedade de maneira conjunta) busca instrumentos para reverter os problemas enfrentados para assim lograr a harmonia social. ${ }^{4}$

Dessa maneira, a atualidade do tema se encontra nas bases do ideário feminista de

1 VERBICARO SOARES, Douglas. Las mujeres y las personas homosexuales en las Fuerzas Armadas. Especial referencia a las FF.AA. brasileñas. Trabajo fin de curso Máster Oficial en Estudios Interdisciplinares de Género. Universidad de Salamanca. Salamanca, Espanha, 2012, p. 20.

2 VERBICARO SOARES, Douglas. Las mujeres y las personas homosexuales en las Fuerzas Armadas. Especial referencia a las FF.AA. brasileñas. Trabajo fin de curso Máster Oficial en Estudios Interdisciplinares de Género. Universidad de Salamanca. Salamanca, Espanha, 2012, p. 21.

3 VERBICARO SOARES, Douglas. Las mujeres y las personas homosexuales en las Fuerzas Armadas. Especial referencia a las FF.AA. brasileñas. Trabajo fin de curso Máster Oficial en Estudios Interdisciplinares de Género. Universidad de Salamanca. Salamanca, Espanha, 2012, p. 22.

4 VERBICARO SOARES, Douglas. Las mujeres y las personas homosexuales en las Fuerzas Armadas. Especial referencia a las FF.AA. brasileñas. Trabajo fin de curso Máster Oficial en Estudios Interdisciplinares de Género. Universidad de Salamanca. Salamanca, Espanha, 2012, p. 20-1. 
igualdade de trato e luta contra os sistemas paternalistas de repressão, violência e submissão. $\mathrm{Na}$ Espanha, o Poder Legislativo já vem desenvolvendo mecanismos de proteção aos coletivos vitimados devido ao gênero, além disso chegou a criar cotas de igualdade e variados instrumentos normativos internacionais sobre estas questóes.

Com base em uma investigação com propósito dedutivo, com uma abordagem qualitativa e pesquisa bibliográfica, o presente estudo esboça um relato da problemática enfrentada pelas mulheres. Como indagaçóes da análise foram feitas algumas perguntas, como por exemplo: o que é gênero? Como foi a história contemporânea das mulheres na Espanha? Quais sãos as medidas tomadas pelo regime para que a mulher se mantenha submissa? Existem políticas educativas de gênero e proteção frente à discriminação?

\section{Explanaçóes sobre gênero e violência}

Para uma melhor compreensão do trabalho apresentado se faz válida a abordagem de alguns temas relevantes, tais como as definiçôes de gênero, assim como de violência. Assim, gênero refere-se às diferenças entre homens e mulheres. Historicamente, o feminismo posicionou os papéis de gênero como construídos socialmente, independente de qualquer base biológica. ${ }^{5}$

Segundo Paul B. Preciado:

El sistema de sexo-género es un sistema de escritura. El cuerpo es un texto socialmente construido, un archivo orgánico de la historia de la humanidad como historia de la producción-reproducción sexual, en la que ciertos códigos se naturalizan, otros quedan elípticos y otros son sistemáticamente eliminados y tachados. ${ }^{6}$

Já violência é um comportamento que causa dano a outra pessoa, ser vivo ou objecto. É toda forma de violência física, sexual o psicológica que coloca em perigo a segurança ou o bem-estar de uma pessoa. Nega-se autonomia, integridade física ou psicológica e mesmo a vida de outro. É o uso excessivo de força, além do necessário ou esperado. O termo deriva do latim violência (que por sua vez o amplo, é qualquer comportamento ou conjunto de deriva de vis, força, vigor); aplicação de força, vigor, contra qualquer coisa ou ente. Assim, a violência diferencia-se de força, palavras que costuma estar próximas na língua e pensamento quotidiano. Enquanto que força designa, em sua acepçáo filosófica, a energia ou "firmeza" de algo, a violência caracteriza-se pela ação corrupta, impaciente e baseada na ira, que não convence ou busca convencer o outro, simplesmente o agride. ${ }^{7}$

Com base nestas ideias preliminares, a violência de género é aquela conduta realizada por uma pessoa, detentora de um sexo, sobre outrem, que poderá se manifestar de diferentes formas, sejam elas materializadas física o psiquicamente. Violência esta que é um flagelo que vive a sociedade e afecta de maneira grave os direitos das mulheres. Essa violência é fruto da

5 VERBICARO SOARES, Douglas. Las mujeres y las personas homosexuales en las Fuerzas Armadas. Especial referencia a las FF.AA. brasileñas. Trabajo fin de curso Máster Oficial en Estudios Interdisciplinares de Género. Universidad de Salamanca. Salamanca, Espanha, 2012, p. 21.

6 PRECIADO, Beatriz. Manifiesto Contrasexual. Colección Argumentos. Barcelona. Espanha: Editorial Anagrama, 2011, p.18

7 VERBICARO SOARES, Douglas. Las mujeres y las personas homosexuales en las Fuerzas Armadas. Especial referencia a las FF.AA. brasileñas. Trabajo fin de curso Máster Oficial en Estudios Interdisciplinares de Género. Universidad de Salamanca. Salamanca, Espanha, 2012, p. 26. 
desigualdade histórica e estrutural entre homens e mulheres. Também de pode dizer que de uma visão androcentrista do mundo, onde o masculino tem valor supostamente superior ao feminino. A violência contra as mulheres é uma forma de violação aos Direitos Humanos de estas mulheres.

Conforme esse entendimento, Espanha decidiu em 2004 promulgar uma Lei de Medidas de Protecção Integral contra a violência de género (Lei Orgânica 1/2004). Em seus términos preceituais, a violência se entenderia: aquelas sofridas pelas mulheres pelas mãos de seus companheiros o ex (o pessoa de igual vínculo). Essa lei busca actuar contra a violência, discriminação, situações de desigualdades entre homens e mulheres. Los poderes públicos no pueden ser ajenos a la violencia de género, que constituye uno de los ataques más flagrantes a derechos fundamentales como la libertad, la igualdad, la vida, la seguridady la no discriminación proclamados en nuestra Constitución. ${ }^{8}$ A violência de gênero se define como: Todo o ato de violência baseado no conceito de sexo feminino, que causa ou é suscetível de causar às mulheres dor ou sofrimento físico, psicológico ou sexual. Não se esquecendo de incluir as ameaças de tais atos e a coação ou a privação arbitrária da liberdade, tanto se se produz na vida pública como na privada (Art.1 da Declaração sobre a Eliminação da Violência contra a Mulher. Nações Unidas, Conferência de Viena, 1993).

\section{O Feminismo e os Estudos de Gênero}

A filósofa e feminista Simone de Beauvoir aplicou o existencialismo para a experiência de vida da mulher: "Ninguém nasce mulher: torna-se mulher". No contexto é um testamento filosófico, entretanto é verdade biologicamente - uma garota precisa passar pela puberdade para se tornar uma mulher - verdade sociológica - a maturidade em relação ao contexto social é aprendida, não instintiva - e verdade nos estudos de gênero - a feminilidade como uma aprendizagem social e cultural. ${ }^{9}$

Para Esther Quinteiro: El derecho es un producto histórico y necesita de un análisis histórico para ser comprendido. Análise essa que deve levar em consideração as variáveis sociológicas, filosóficas, religiosas e outras e que, também, faz parte de uma evolução para se descobrir o direito das mulheres. É válido lembrar que o movimento feminista, impulsionado na Europa por pensadoras como Simone de Beauvoir, em plenos anos sessenta por Betty Friedan nos Estados Unidos, contribuiu para que milhares de mulheres se repensassem a si mesmas e se mobilizassem para exigir mudanças que colocassem fim a uma situação de desigualdade em que se encontravam perante os homens. ${ }^{10}$ Hoy las mujeres son sujetos de la historia. Los derechos humanos nacen de la modernidad y se integra en la según mitad del siglo XX. ${ }^{11}$

8 VERBICARO SOARES, Douglas. Las mujeres y las personas homosexuales en las Fuerzas Armadas. Especial referencia a las FF.AA. brasileñas. Trabajo fin de curso Máster Oficial en Estudios Interdisciplinares de Género. Universidad de Salamanca. Salamanca, Espanha, 2012, p. 22.

9 VERBICARO SOARES, Douglas. Las mujeres y las personas homosexuales en las Fuerzas Armadas. Especial referencia a las FF.AA. brasileñas. Trabajo fin de curso Máster Oficial en Estudios Interdisciplinares de Género. Universidad de Salamanca. Salamanca, Espanha, 2012, p. 22-3.

10 SEGARRA Marta; CARABİ Àngels. Nuevas Masculinidades. Construyendo nuevas masculinidades: Una introducción. Icaria, mujeres y culturas. Barcelona, Espanha, 2000, p. 15.

11 É válido ressaltar que os estudos sobre a situação das mulheres tiveram o seu início nos anos 60. Nos EUA, esses primeiros passos se intensificam como o movimento feminista. Na Europa se desenvolve com a Segunda Guerra Mundial. As mulheres começam a desempenhar um papel significativo nas revoluçôes industriais. 
Importante é a ideia majoritária que a violência esteve presente nas sociedades, mas sua idéia e compreensão de uma verdadeira violação pareciam esquecidas. Faz-se necessária a citação de determinado texto encontrado no livro de Marta Segarra, chamado: Novas Masculinidades, que dizia:

O varão de acordo com a confirmação de grandes pensadores e filósofos como Schopenhauer, Nietzsche, Hegel e Kierkegaard e, como explora Amelia Valcárcel, em a política das mulheres (1997), foi considerado superior a mulher, que quer dizer que a mulher foi configurada como espelho das necessidades do homem, sendo detentora da submissão, da passividade, a beleza, características que se considerável essencialmente femininas. Essa formação cultural vinculou as mulheres a cuidar de seus filhos e da família, se mantendo alijada das decisóes de estado. O homem se estabeleceu como sujeito do seu próprio desejo, ativo, não necessariamente bonito e autorizado a desatender o cuidado da família. A mulher se conformou em uma ética relacional, o varão, por outro lado, assumiu o individualismo como valor de êxito. ${ }^{12}$

Com base nesse entendimento é cristalina a compreensão de que o fator cultural é essencial para determinar o papel participativo ou não da mulher em uma determinada sociedade. Esta é a responsável por estabelecer essa participação, seja numa família, numa escola, num trabalho etc. É válido lembrar que a história é testemunha desses momentos.

A violência contra a mulher, de acordo com a Declaração sobre a eliminação da violência contra a mulher da ONU (Organização das Naçóes Unidas) estabelece que esta fosse, além da violência realizada por um Estado, a violência física, sexual, psicológica no âmbito familiar, os espancamentos, o abuso sexual das filhas pelos pais, a violência relacionada com o dote, violação no matrimônio, mutilação genital feminina e outras práticas tradicionais que são danosas a mulher, violência fora do âmbito conjugal e a violência ligada a exploração, a violência física, sexual, psicológica que tem lugar dentro da comunidade em geral, incluída a violação, os abusos sexuais, o assédio sexual e a intimidação no trabalho, nas instituições educativas e em qualquer outro lugar. ${ }^{13}$

Segundo o Atlas do Estado da Mulher no Mundo, muitas são mulheres do mundo vivem sobre a ameaça da violação. O perigo principal geralmente está na sua casa ou vem de homens que as conhecem. Na maioria das sociedades, a responsabilidade de manter a pureza sexual e a honra é imposta à mulher. Portanto, é a mulher e não o violador que carrega a vergonha e o sentido de culpa. ${ }^{14}$ Dessa maneira, fica claro que, a partir do momento em que a democracia perde o seu principal objetivo, o de representar os anseios do povo, ou o fato de náo se ter uma democracia para garantir a vontade popular em determinado Estado, as intolerâncias, as arbitrariedades acabam se intensificando. Assim, a real vontade popular é suprimida em favor de idéias revolucionárias, que surgem com o falso teor de suprimir as calamidades políticas, sociais e econômicas, construindo um sistema mais justo e igual.

Mudar a difícil realidade só poderá ser conseguida a partir de uma real sensibilização da sociedade em geral, onde os homens, detentores de um domínio predominante, possam permitir que a mulher garantisse a sua efetiva participação social, em igualdades de condiçóes

12 SEGARRA Marta; CARABÍ Àngels. Nuevas Masculinidades. Construyendo nuevas masculinidades: Una introducción. Icaria, mujeres y culturas. Barcelona, 2000, p. 16.

13 AMNESTY INTERNATIONAL (EDAI). Los derechos humanos, un derecho de la mujer. Editorial Amnesty International. Madri, Espanha, 1995, p. 12-14.

14 SEAGER, Joni. ATLAS Akal. Del Estado de la Mujer en el Mundo, 1997, p. 56. 
com os homens. É o que preceitua o próprio ideal feminista, o de não prevalência da mulher em sua relação com o homem em sociedade e sim o de igual participação. É o reconhecimento da violência e luta pela sua supressão.

Os estudos sobre as relaçôes de gênero ${ }^{15}$ contribuíram para se compreender o sofrimento feminino, a estudar os seus transtornos de gênero e não mais velos como algo patológico para as mulheres. Essa mudança foi possível porque a "anormalidade" feminina foi entendida como uma construção da cultura patriarcal para as mulheres que pode e deve ser desconstruída e reconstruída com uma proposta de igualdade de trato entre os gêneros. ${ }^{16}$

\section{História contemporânea das mulheres na Espanha}

Durante a Segunda República na Espanha, surgiu todo um debate sobre a situação das mulheres (legislação progressista), com idéias importantes de Clara Campoamor, responsáveis por alteraçôes significativas e conquistas para as mulheres, assim como: a Constituição de 1931, voto, divórcio, aborto, possibilitando a ampliação dos estudos das mulheres, conseqüentemente, diminuindo o analfabetismo, regulamento de deveres e obrigaçóes das mulheres no mercado de trabalho. De 1931 a 1936, as mulheres estavam mais intelectualizadas e podiam, incluso, cobrar por seus trabalhos, vão as universidades, podem se casar num âmbito civil e não somente no regime religioso, podem controlar a quantidade de filhos. Mas essas conquistas duraram apenas cinco anos. A população na Espanha era muito conservadora, então não foi difícil que depois da ditadura, as idéias fossem privadas e retrocedessem aos atrasos, nesse contexto, a alfabetizaçáo não foi completa e as conquistas anteriores foram prejudicadas, gerando outros problemas para o respeito aos direitos das mulheres. ${ }^{17}$

Em 1931 acontecem as primeiras eleiçóes realizadas pelo partido radical. No ano de 1933, as mulheres votam pela primeira vez na Espanha e ganhou o partido conservador, ganhou a direita no poder. Nesse período o voto feminino foi um voto conservador, a maioria das mulheres não teria acesso aos programas políticos, não sabiam ler, e não tinham conhecimento do mundo externo, fora do âmbito privado. O mesmo caso ocorreu em países mulçumanos, que em geral, são sociedades que não possuem instrumentos para a inclusão e emancipação das mulheres em sociedades e o que prevalece é a submissão ao homem (pai, marido ou filho). O quadro político era composto por dois bandos: o primeiro deles, o bando de Franco: Grupo de direita ou de nacionais. O Segundo grupo era os dos republicanos, ou os da esquerda. É importante recordar que nesse período se institui na Espanha uma associação de mulheres de direita, isso é importante para demonstrar que as mulheres começavam a se organizarem, mas que por sua vez não representava uma real vitória para as mulheres, pois essa associação tinha por objetivo a

15 Um exemplo para os estudos sobre a materia de gênero encontra-se na criançao do Centro de Estudos das mulheres em Salamanca: "Continuamente se habla de sensibilización en el tema y una necesaria formación especifica sobre género, algo a lo que tanto la USAL como la UPSA han decidido unirse dedicando estudios especializados. Asi, la USAL cuenta con un Centro de Estudios de la Mujer, dirigido por Esther Martinez que inició realmente sus formaciones en 2002 cubriendo necesidades formativas de grado y posgrado, investigando y siendo herramienta de asesoramiento docente para la universidad en materia de género". CONTRA LOS MALOS TRATOS. Reportaje violencia de género. Tribuna Universitaria. Salamanca no 507. 2430 Noviembre 2008, p. 12-13.

16 SEGARRA Marta; CARABÍ Àngels. Nuevas Masculinidades. Construyendo nuevas masculinidades: Una introducción. Icaria, mujeres y culturas. Barcelona, 2000, p. 43.

17 VERBICARO SOARES, Douglas. Las mujeres y las personas homosexuales en las Fuerzas Armadas. Especial referencia a las FF.AA. brasileñas. Trabajo fin de curso Máster Oficial en Estudios Interdisciplinares de Género. Universidad de Salamanca. Salamanca, Espanha, 2012, p. 25. 
organização de um movimento com antifeministas, não se queria a emancipação da mulher e, sim, todo um contrário. Essa seçáo feminina era pertencente ao grupo de Jose Antônio Primo de Rivera, e a seção feminina ${ }^{18}$ chefiada por Pillar Primo de Rivera. Com as chamadas: "mulheres, a pátria necessita sua ajuda”, o Sistema Totalitário espanhol buscava manter as mulheres sob um regime conservador.

A participação de homens e mulheres era realizada da seguinte forma: os homens iam para a guerra e as mulheres se encarregavam de cultivar nos campos, fazer as roupas, cultivam os campos. Nesse momento se nota uma carência e se inicia a necessária participação da mulher no mercado de trabalho, ou melhor, a ocupação dos postos deixados pelos homens na guerra e a tomada dos mesmos pelo trabalho feminino, que na época não recebiam salários pelo lavoro, mas sim comida pela mão de obra realizada. ${ }^{19}$

Com o passar dos tempos, o Comitê Nacional de mulheres contra a guerra e o fascismo, chamou as mulheres para combater o Regime. Em 1939, após uma Espanha destruída, ganharam os militares a guerra e, até o ano de1975, Franco começou uma ruptura, com um novo papel para as mulheres, ou melhor, um retrocesso na participação da mulher. Os anos que seguiram foram marcados pela implantação de valores patriarcais e a consolidação das seçôes femininas na sociedade, reforçando a submissão da mulher em relação ao homem. Pillar Rivera chegou a dizer: "que a sua missão deveria ser a de ajuda, pois a função de direção só era pertencente aos homens". O que representa esse momento na história espanhola? As mulheres voltam ao âmbito privado e doméstico (responsável pela educação dos filhos, cuidados do marido e uma vida doméstica), sendo que os homens se manteriam únicos no domínio do sistema público. ${ }^{20} \mathrm{Um}$ verdadeiro retrocesso para as mulheres.

\section{Quais sãos as medidas tomadas pelo regime para que a mulher se mantenha submissa?}

Nesse período foi estabelecia uma idade para que as mulheres contraíssem o matrimônio, medidas de incentivo a natalidade e ao número de filhos no casamento, assim como, também, que a mulher ficasse a cargo das atividades do lar, estava proibido o aborto e qualquer tipo de uso

18 Essa mesma seção feminista era responsável pelas maiores arbitrariedades aos direitos das mulheres, com forte ideologia de submissão e inferiorização da mulher, seja em relação ao homem e também a sua própria situação em sociedade. Uma frase merece ser citada atribuída ao pensamento das seçóes feministas, senão vejamos: "a vida da mulher seria a de encontrar a alguém a quem se submeter".

19 VERBICARO SOARES, Douglas. Las mujeres y las personas homosexuales en las Fuerzas Armadas. Especial referencia a las FF.AA. brasileñas. Trabajo fin de curso Máster Oficial en Estudios Interdisciplinares de Género. Universidad de Salamanca. Salamanca, Espanha, 2012, p. 25.

$20 \mathrm{Na}$ Espanha algo curioso acontece, nos anos de 1936-1975, período finalizado pela Morte de Franco, o antigo código de 1808 - código napoleônico, volta a ter vigor nesse país. E o que ocorre com esse retorno? Fica proibido o matrimonio civil, só estaria em vigor o casamento religioso, também se proíbe o divórcio e, quem tinha se separado anteriormente, volta a estar casado. O controle de fertilidade se impede. Todas essas medidas são implementadas pelo Sistema Totalitário de Franco. Aqui se considera que a família é a célula base de uma sociedade e é superior a qualquer lei positiva, nesse caso, o sistema de Franco engrandece a família e foi criado um regulamento próprio para cuidar dessa família, ou seja, elimina certos mecanismos concedidos, tais como o do plus familiar (que era concedido quando a mulher trabalhava fora de casa), e implementa mecanismos de controle que façam com que a mulher fique em casa fazendo um papel doméstico e não de emancipação (A excedência forçosa). Por sua vez essa ideia consiste em dizer que a partir do casamento e de uma vida matrimonial, a mulher que antes desempenhava um trabalho fora de casa, enquanto solteira, deveria deixar o mesmo trabalho depois de casada, pois como o casamento, a sua função e responsabilidade seria a de servir ao marido e ficando a este último a responsabilidade pelo sustento da família. VERBICARO SOARES, Douglas. Las mujeres y las personas homosexuales en las Fuerzas Armadas. Especial referencia a las FF.AA. brasileñas. Trabajo fin de curso Máster Oficial en Estudios Interdisciplinares de Género. Universidad de Salamanca. Salamanca, Espanha, 2012, p. 25. 
de anticoncepcionais. Essas medidas adotadas eram fortes mecanismos de controle do Sistema Totalitário de Franco. ${ }^{21}$

É imperioso destacar que muitas foram as crueldades cometidas pelo Regime de Franco, a mulher deveria seguir o marido, e durante a Ditadura Franquista, a mesma deveria seguir a nacionalidade do marido. No caso de que a mulher se tornasse viúva, e se casasse depois, ela perderia a guarda dos filhos, as mulheres náo poderiam autorizar a venda e dispor de bens econômicos do casal, esse poder ela limitado a figura do homem. O marido era o representante legal da esposa, que ficava impedida de firmar contratos, em muitos casos, as mulheres nem sabiam como era a situação econômica da família, pois esses assuntos eram exclusivos dos homens, era como uma infantilização feminina, tornando as dependentes dos homens. Nessa época as mulheres não tinham acesso à licença marital, não podendo trabalhar, cobrar um salário, exercer o comercio, abrir conta em bancos, tirar passaporte, e nem carteira para conduzir. Se as mulheres não contassem com a autorização do marido, não podiam receber herança o vender ou hipotecar seus bens entre outros. ${ }^{22}$

La que perdía totalmente su personalidad, su capacidad de obrar, era la (mujer) casada, la cual desde el mismo momento de contraer matrimonio pasaba a ser una menor, y el mismo Código Civil lo recogió muy claramente en su artículo 1263 (sobre quienes no podían prestar consentimiento válido) que situaba a la mujer casada, entre los menores, los locos o dementes y los sordomudos que no sabían escribir. $^{23}$

Sem dúvida uma triste realidade de opressão vivida pelas mulheres em um período sombrio da história da Espanha.

\section{Políticas educativas de gênero e proteção frente à discriminação}

Notam-se que os temas sobre a igualdade de gênero direcionados pelas políticas educacionais vêm assumindo um papel cada vez mais abrangente pelo mundo. Variados são os Instrumentos criados pelo âmbito internacional para a proteção da dignidade das pessoas, em especial as mulheres: La Conferencia Internacional de Derechos Humanos (Teherán, 1968). La Convención sobre la eliminación de todas las formas de discriminación contra la mujer (1979). La Convención sobre los Derechos del Niño (1989). La Conferencia Mundial de Derechos Humanos (Viena, 1993). La Conferencia Internacional sobre Población y Desarrollo (Cairo, 1994). La Conferencia Mundial sobre condición jurídica y social de las mujeres (Beijing, 1995). ${ }^{24}$

Quanto a estas ideias preliminares:

A sexualidade refere-se às elaboraçóes culturais sobre os prazeres e os intercâmbios sociais e corporais que compreendem desde o erotismo, o desejo e o afeto, até noçôes relativas à saúde, à reprodução, ao uso de tecnologias e ao exercício do

21 VERBICARO SOARES, Douglas. Las mujeres y las personas homosexuales en las Fuerzas Armadas. Especial referencia a las FF.AA. brasileñas. Trabajo fin de curso Máster Oficial en Estudios Interdisciplinares de Género. Universidad de Salamanca. Salamanca, Espanha, 2012, p. 25.

22 TELO, María. Ponencia oferecida no Instituto Cervantes dia 23 de novembro de 2005. Disponível em: <http:// www.laotrapagina.com/articulo-168.html>. Acesso em: 06 jan. 2022.

23 TELO, María. Ponencia oferecida no Instituto Cervantes dia 23 de novembro de 2005. Disponível em: <http:// www.laotrapagina.com/articulo-168.html>. Acesso em: 06 jan. 2022.

24 VERBICARO SOARES, Douglas. Las mujeres y las personas homosexuales en las Fuerzas Armadas. Especial referencia a las FF.AA. brasileñas. Trabajo fin de curso Máster Oficial en Estudios Interdisciplinares de Género. Universidad de Salamanca. Salamanca, Espanha, 2012, p. 35-8. 
poder na sociedade. As definiçóes atuais da sexualidade abarcam, nas ciências sociais, significados, ideias, desejos, sensaçôes, emoçóes, experiências, condutas, proibiçóes, modelos e fantasias que são configurados de modos diversos em diferentes contextos sociais e períodos históricos. Trata-se, portanto, de um conceito dinâmico que vai evolucionando e que está sujeito a diversos usos, múltiplas e contraditórias interpretaçôes e que se encontra sujeito a debates e a disputas políticas. ${ }^{25}$

Para o conceito de Direitos Humanos: embora existam denominaçóes distintas encontradas na doutrina de diversos países, e também, tendo alguns posicionamentos restritos a bases históricas ou culturais, não podem comprometer a essência desse tema; uma vez que, tais diferenças estão apenas relacionadas às origens desses pensamentos, sejam elas de traços anglo-americanos ou latinos, sempre irâo tratar dos direitos humanos, mesmo que de forma específica. ${ }^{26}$ Os Direitos Humanos, independentemente de serem conhecidos como direitos do homem; direitos individuais; direitos fundamentais, direitos do cidadão, têm o objetivo de manter a integridade dos direitos que pertencem e são inerentes ao homem, sendo ele um ser racional, podendo ou não ser visto de forma individualizada ou coletiva na sociedade. ${ }^{27}$ Ao recordar as palavras da Dra. Esther Martínez Quinteiro, em suas aulas na Universidade de Salamanca sobre o tema dos Direitos Humanos, se somarão a interpretação que os mesmos direitos são: "um conjunto de ideias, de mecanismos que primam pela proteção do homem e suas relaçôes com os demais”. Essas subdivisôes citadas por diferentes autores são meramente metodológicas, tornando as diversas denominações semelhantes às espécies (específico), na qual os direitos humanos fazem parte de um construído mais amplo (gênero), ou seja: num sentido mais abrangente. ${ }^{28}$

A sexualidade é fruto da construção do comportamento humano. Construção essa que diz respeito a hábitos, práticas, comportamentos, pensamentos de uma pessoa com a temática do sexo e seu posterior relacionamento social. Várias são as áreas que procuram definir e estudar a sexualidade humana, desde a biologia, passando pela teologia, psicanálise, sociologia, antropologia, direito e muitas outras.

Para Félix López Sánchez, ao definir as características da sexualidade humana se estende da seguinte maneira:

O ser humano inicia sua história quando o processo de desenvolvimento das diferentes espécies sexuadas levava um largo caminho. Aparece, portanto, compartindo com todas as espécies sexuadas algumas características essenciais, entre elas as que destacam a identidade sexual (fêmea e macho), róis sexuais na reprodução e criança, afetos sexuais, como o desejo e a atração, e os afetos sociais, como os vínculos entre progenitores e crias. Mas, esse processo adquire, no caso da nossa espécie, características próprias, que supõem uma diferenciação qualitativa do resto das outras espécies. Os seres humanos, em efeito são: 1) indivíduos diferentes genética e culturalmente, 2) possuímos uma identidade sexual que depende das características biológicas do homem e da mulher, 3) temos uma identidade sexual sobre as que as outras culturas foram construindo uns róis de gênero, quase sempre discriminatórios para com as mulheres, que

25 MANUAL DE COMUNICAÇAO LGBT. Lésbicas, Gays, Bissexuais, Travestis e Transexuais. Brasília. Brasil, 2010 , p. 9.

26 OLIVEIRA, Almir. Curso de Direitos Humanos. Rio de Janeiro. Brasil: Ed. Forense, 2000, p. 69-70.

27 OLIVEIRA, Almir. Curso de Direitos Humanos. Rio de Janeiro. Brasil: Ed. Forense, 2000, p. 16.

28 VERBICARO SOARES, Douglas. Las mujeres y las personas homosexuales en las Fuerzas Armadas. Especial referencia a las FF.AA. brasileñas. Trabajo fin de curso Máster Oficial en Estudios Interdisciplinares de Género. Universidad de Salamanca. Salamanca, Espanha, 2012, p. 29. 
regulam numerosos aspectos da vida social das pessoas, 4) possuímos, como ocorre em outras espécies sexuadas, uma forte motivação sexual (desejo e atração) e sua atividade sexual está premiada (prazer sexual), 5) temos a característica de que a sexualidade é uma dimensão mais rica e complexa que nos limita a uma mera função reprodutora. ${ }^{29}$

No que diz respeito aos Direitos Sexuais ${ }^{30}$, válida é a exemplificação da existência da Declaração que versa sobre o reconhecimento e proteção dos Direitos Humanos. Essa Declaração ${ }^{31}$ :

29 SÁNCHEZ, Félix López. La Educación Sexual. Biblioteca Nueva. Madrid, Espanha, 2005, p. 20-22.

30 A ideia de equidade sexual acompanha uma mudança epistêmica na área da sexualidade. Os direitos sexuais surgem num contexto histórico em que se destaca também a força do discurso favorável aos direitos humanos. Os grupos subordinados que se organizam e se mobilizam politicamente nos movimentos sociais, sobretudo a partir dos anos 1950, contribuiram com o contexto e impulsionaram o posicionamento teóricolacadêmico dos ditos especialistas das ciências na revisão em modificação dos enquadramentos patológicos e das definiçōes de algumas doenças, antes usadas como justificativa para a exclusão social e a privação de direitos desses sujeitos discriminados. JUNQUEIRA, Rogério Diniz. Diversidade Sexual na Educação: problematizações sobre a homofobia nas escolas. Coleção Educação para todos. Brasília, Brasil, 2009. Texto de Jimena Furlani: "Direitos Humanos, Direitos Sexuais e pedagogia queer: o que essas abordagens têm a dizer à educação sexual?”, p. 304.

31 Com base nos textos utilizados em classe, na matéria de Direitos Humanos e Sexualidade, ministrados pela Dra. Cristina Amich Elías. Matéria essa que pertence ao Curso de Doutorado: Passado e Presente dos Direitos Humanos da Universidade de Salamanca, Espanha. Pode-se usar de maneira auxiliar na compreensão de textos normativos sobre a temática de direitos sexuais e, por conseguinte, em anseios para a efetivação dos Direitos sexuais como Direitos Humanos. Nesse sentido, adota-se um texto original (em língua inglesa) que pertencente ao material da IPPF (International Planned Parenthood Federation: Charter of sexual and reproductive rights), uma entidade privada, que pode demonstrar um posicionamento parcial sobre a temática de direitos segundo suas próprias convicçóes, mas que podem aludir idéias válidas sobre a compreensão dos Direitos Humanos, senão vejamos alguns preceitos: Condenação de todas as ameaças à vida de uma pessoa. The Right to Life Direito à vida: - A vida de nenhuma mulher deve ser colocada em risco ou ameaçada devido à gravidez, - A vida de nenhuma criança deverá ser colocada em risco ou violada por sua condição se pertencer ao sexo (masculino ou feminino), - A vida de qualquer pessoa não poderá ser colocada em risco ou ameaça por ausência de cuidados à saúde e a informaçáo ou serviços relacionados à saúde sexual e/ou reprodutiva.

Condenação de todas as formas de violaçáo, exploraçáo, imposição na liberdade sexual de uma pessoa seria condenável. The Right to Liberty and Security of the Person - Direito à liberdade e à seguridade pessoal: - Toda as pessoas têm seus direitos de serem livres na escolha e no controle de suas vidas sexuais e reprodutivas e também de respeitar os direitos dos demais, - Todas as pessoas têm o direito de não serem submetidas à intervenção médica relacionada a sua vida reprodutiva e sexual, sem o seu consentimento e informaçáo, - Todas as mulheres têm direitos de serem livres de qualquer forma de mutilação genital, - Todas as pessoas têm o direito de estarem livres da imposição e de exteriorizar o medo, da vergonha, culpa, crenças baseadas em mitos e outros fatores psicológicos que inibem as suas respostas ou prejudiquem suas vidas sexuais.

Condenaçáo ao não respeito à igualdade sexual, ou seja, libertação de todas as formas de discriminação. The Right to Equality, and to be free from all forms of discrimination - Direito à igualdade e de ser livre de todas as formas de discriminação: - nenhuma pessoa deverá ser discriminada em sua vida sexual e/ou reprodutiva, no seu acesso aos métodos de proteção da saúde, ou serviços devido à raça, cor, sexo ou orientação sexual, status marital, posição familiar, idade, língua, religião, política ou outra opinião, origem nacional ou social etc.

Condenação a todas as formas de arbitrariedade e interferência na vida privada, família, casa ou correspondência de uma pessoa. The Right to Privacy - Direito à privacidade: - Todas as pessoas têm direito de manter sua privacidade na adoção de qualquer serviço sexual ou reprodutivo, incluindo a informação e o aconselhamento, - Todas as mulheres têm o direito à escolher a reprodução autônoma, inclusive no que diz respeito ao aborto seguro, - Todas as pessoas têm o direito de expressar sua orientação sexual na proporção de ter uma sana e satisfatória vida sexual, respeitando as decisóes e o bem-estar dos demais e etc.

Condenação a todas as formas que violem o direito de liberdade ou de pensamento, consciência e de religiāo. The Right to Freedom of Thought - Direito à liberdade de pensamento: - Todas as pessoas têm o direito à liberdade de pensamento e de se manifestar relacionado às suas vidas reprodutivas e sexuais, - Todas as pessoas têm o direito a proteçáo contra restriçóes em grau de pensamento, consciência e religiáo para o seu acesso à educaçáo e a informação relativa à saúde sexual e reprodutiva, - Os profissionais da saúde têm o direito de consciência de objeção para a negação de prestar serviços abortivos e contraceptivos e também de direcionar os pacientes que desejem praticar essas açóes a outros profissionais que estariam dispostos a realizar esse serviço. Esses direitos não se mantêm em casos de emergências que representem um risco a vida de uma pessoa.

Reconhecimento que todas as pessoas têm o direito a uma educação e, em particular, q uma educação específica que retrate a saúde e o bem-estar das pessoas e de familiares, incluindo informação e conselhos na vida sexual e reprodutiva e em direitos. The Right to Information and Education - Direito à informaçáo e à educaçáo: - Todas as pessoas têm direito ao acesso a uma educação e correta informação relacionada à sua vida reprodutiva e sexual, direitos e responsabilidades de gênero, livres de estereótipos, apresentados de forma objetiva, crítica e pluralista, - Todas as pessoas têm o direito de uma educação suficiente e informação satisfatória, que assegurem que qualquer decisão relacionada com a saúde sexual e reprodutiva, sejam realizadas sem o consentimento pleno, livre e informado, etc.

Reconhecimento que todas as pessoas têm o direito de náo casar ou de escolher com quem querem casar e de planejar uma família, independentemente da idade, nacionalidade, religião e etc. The Right to Choose Whether 
dos Direitos Sexuais foi uma elaboração do Congresso Mundial de Sexologia realizado em Valência, cidade espanhola, no ano de 1997. Posteriormente, foi revisada e aprovada pela Assembléia Geral da Associação Mundial de Sexologia (WAS - World Association for Sexology) em 1999, no $14^{\circ}$ Congresso Mundial de Sexologia (Hong Kong, República Popular de China). ${ }^{32}$

Segundo a Doutora em educadora sexual, Jimena Furlani, por mais que essa Declaração tenha sido elaborada no sentido generalizado, no que diz respeito às diversas identidades sexuais, a Declaração pode ser entendida como um documento político, de reivindicaçóes, conquistas, reconhecimento aos grupos e/ou sujeitos subordinados e de respeito a eles. Para a autora:

Os direitos sexuais são direitos humanos universais baseados na inerente liberdade, dignidade e igualdade de todos os seres humanos. Uma vez que a saúde sexual é um direito fundamental, entâo a saúde sexual deve ser um direito humano básico. Para assegurarmos que os seres humanos e a sociedade desenvolvam uma sexualidade saudável, os direitos sexuais, a seguir, devem ser reconhecidos, promovidos e respeitados e defendidos por todas as sociedades de todas as maneiras. Saúde sexual é o resultado de um ambiente que reconhece, respeita e exercita estes direitos sexuais. ${ }^{33}$

Vários outros textos normativos tratam de temas relacionados com a sexualidade e os direitos sexuais como Direitos humanos:

Pacto Internacional dos Direitos Civis e Políticos de 1966. Assinado pelo Brasil somente em 1992. Pacto esse que garante a todas as pessoas subordinadas à jurisdição de todos os países que firmaram esse Pacto Internacional de Direitos Civis e políticos. Ressalta-se em dois de seus artigos a importância de não discriminar, seja qual foi o motivo dessa discriminação (raça, sexo, religião, opinião, situação etc.):

Artigo $2^{\circ}-1$. Os Estados-partes no presente Pacto comprometem-se a garantir a todos os indivíduos que se encontrem em seu território e que estejam sujeitos à sua jurisdição os direitos reconhecidos no presente Pacto, sem discriminaçáo alguma por motivo de raça, cor, sexo, língua, religiáo, opinião política ou de qualquer outra natureza, origem nacional ou social, situação. Artigo 26 - Todas as pessoas são iguais perante a lei e têm direito, sem discriminação alguma, a igual proteção da lei. A este respeito, a lei deverá proibir qualquer forma de discriminação e garantir a todas as pessoas proteção igual e eficaz contra qualquer

or not to Marry and to Found and Plan a Family - Direito de escolher casar ou de não planear família: - Todas as pessoas têm direitos de proteção quanto a imposição de um casamento, as pessoas envolvidas não devem constituir matrimônio nos casos de ausência de um completo e livre consentimento, - todas as pessoas têm direitos ao acesso aos cuidados dos serviços médicos, incluindo aqueles que são inférteis, ou cuja fertilidade é são prejudicados pela transmissão de infecçôes sexuais.

Reconhecimento que qualquer pessoa tem o direito de ser livre para se reunir em assembléia e associação. The right to freedom of Assembly and Political Participation. Direito à liberdade de reunião e de participação política: - Todas as pessoas têm o direito de associaçáo com o objetivo de promover a saúde sexual e/ou reprodutiva, o bem estar sexual e os direitos relacionados com essa temática.

Reconhecimento que todas pessoas têm o direito de não ser submetidas à tortura ou cruel e desumano tratamento ou punido, ou ser submetido a tratamento médico e científico sem liberdade ou consentimento pleno. The Right to be Free from Torture and Ill Treatment. Direito de não ser submetido à tortura e a tratamento desumano ou degradante: Todas as pessoas têm o direito de serem protegidas contra o rapto, violaçóes, abusos sexuais e o assédio sexual. IPPF (International Planned Parenthood Federation): Charter of sexual and reproductive rights. Disponivel em: <http://www.ippf.org/en/Resources/Statements/IPPF+Charter+on+Sexual+and+Reproductive+Rights. htm>. Acesso em: 06 jan. 2022.

32 JUNQUEIRA, Rogério Diniz. Diversidade Sexual na Educação: problematizaçôes sobre a homofobia nas escolas. Coleção Educação para todos. Brasília. Brasil. 2009. Texto de Jimena Furlani: "Direitos Humanos, Direitos Sexuais e pedagogia queer: o que essas abordagens têm a dizer à educação sexual?”, p. 301.

33 JUNQUEIRA, Rogério Diniz. Diversidade Sexual na Educação: problematizaçôes sobre a homofobia nas escolas. Coleção Educação para todos. Brasília. Brasil. 2009. Texto de Jimena Furlani: "Direitos Humanos, Direitos Sexuais e pedagogia queer: o que essas abordagens têm a dizer à educação sexual?”, p. 302. 
discriminação por motivo de raça, cor, sexo, língua, religião, opinião política ou de outra natureza, origem nacional ou social, situação econômica, nascimento ou qualquer outra situação. ${ }^{34}$

Outro Texto Internacional que merece ser ressaltado é o Pacto Internacional dos Direitos Econômicos, Sociais e Culturais, 1966. Pacto esse que ressalta o comprometimento dos Estados-membros em garantir o cumprimento de seus preceitos normativos sem a incidência de discriminação. Discriminação essa estendida a qualquer natureza, raça, cor, sexo, língua, religiáo opinião, situação econômica etc. São válidos os artigos infracitados:

Artigo $1^{\mathrm{o}}-1$. Todos os povos têm direito à autodeterminação. Em virtude desse direito, determinam livremente seu estatuto político e asseguram livremente seu desenvolvimento econômico, social e cultural. Artigo $2^{\circ}$ - 1. Cada Estadoparte no presente Pacto compromete-se a adotar medidas, tanto por esforço próprio como pela assistência e cooperação internacionais, principalmente nos planos econômico e técnico, até o máximo de seus recursos disponíveis, que visem a assegurar, progressivamente, por todos os meios apropriados, o pleno exercício dos direitos reconhecidos no presente Pacto, incluindo, em particular, a adoção de medidas legislativas. Parágrafo 2. Os Estados-partes no presente Pacto comprometem-se a garantir que os direitos nele enunciados se exercerão sem discriminação alguma por motivo de raça, cor, sexo, língua, religiáo, opiniấo política ou de qualquer outra natureza, origem nacional ou social, situação econômica, nascimento ou qualquer outra situação. ${ }^{35}$

Menciona-se, também, a Convenção para a Eliminação de Todas as Formas de Discriminação contra a Mulher - CEDAW, 1979. A presente Convenção foi provada pela Organização das Naçôes Unidas em 1979, tendo entrado em vigor apenas em 1981. A CEDAW foi ratificada pelo governo brasileiro em 1984. A Convenção fundamenta-se na obrigação dos Estados de assegurar a igualdade entre homens e mulheres e eliminar todos os tipos de discriminação contra a mulher. Essa Convenção representa um dos primeiros mecanismos internacionais que preceitua a efetivação dos direitos das mulheres e a fundamental garantia de igualdade de trato entre homens e mulheres:

Artigo $1^{\circ}$ - Para fins da presente Convenção, a expressão "discriminação contra a mulher" significará toda distinção, exclusão ou restrição baseada no sexo e que tenha por objeto ou resultado prejudicar ou anular o reconhecimento, gozo ou exercício pela mulher, independentemente de seu estado civil, com base na igualdade do homem e da mulher, dos direitos humanos e liberdades fundamentais nos campos político, econômico, social, cultural e civil ou em qualquer outro campo. ${ }^{36}$

Nessa linha de exemplificaçôes segue o Protocolo Facultativo à CEDAW, 1999, (adotado pela Assembleia Geral da ONU em 1999, ratificado pelo Brasil em 2001 e firmado

34 ROLIM. Pacto Internacional dos Direitos Civis e Politicos (1966). Disponível em: <http://www.rolim.com. br/2002/_pdfs/067.pdf>. Acesso em: 06 jan. 2022.

35 PGE. Pacto Internacional dos Direitos Econômicos, Sociais e Culturais de 1966. Disponível em: <http://www.pge. sp.gov.br/centrodeestudos/bibliotecavirtual/instrumentos/direitos.htm>. Acesso em: 06 jan. 2022.

36 A CEDAW teve sua origem no esforço do movimento feminista internacional em comprometer os EstadosMembros das Naçôes Unidas na condenação da discriminação contra a mulher em todas as suas formas e manifestaçóes. Essa Convenção resultou da I Conferência Mundial da Mulher, realizada pelas Nações Unidas na Cidade do México, em 1975.

VIOLENCIA MULHER. CEDAW-Convenção sobre a Eliminação de Todas as Formas de Discriminação contra a Mulher (1979). Disponível em: <http://www.violenciamulher.org.br/index.php?option=com_content\&view=a rticle\&id=1229:cedaw-convencao-sobre-a-eliminacao-de-todas-as-formas-de-discriminacao-contra-a-mulher1979\&catid=5: convencoes-e-outros-documentos-internacionais\&Itemid=10.htm>. Acesso em: 06 jan. 2022. 
pelo Congresso Nacional brasileiro em 2002). Com assinatura do Protocolo Facultativo pelo Congresso Nacional o Brasil se compromete em resguardar o cumprimento das normas contidas e se faz responsável ao reconhecer a competência do Comitê CEDAW para receber denúncias de descumprimento de suas normas integrantes da Convenção para a Eliminação de Todas as Formas de Discriminação contra a Mulher. Através dessa ratificação do Protocolo Facultativo, permite-se proteger as pessoas ou grupo de violaçôes a seus direitos e respectivas denúncias ao Comitê nos casos de desrespeitos às normas presentes na Convenção, possibilitando acesso à justiça internacional às mulheres vítimas de qualquer origem de violência. ${ }^{37}$

Não menos importante é a Declaração e Plataforma de Ação da III Conferência Mundial sobre Direitos Humanos - Viena, 1993. Essa Declaração visa a promover os objetivos da igualdade, desenvolvimento e paz para todas as mulheres, em todos os lugares do mundo, de acordo com os interesses humanitários. A Declaração e Plataforma de Ação de Viena preceituam que a violência baseada no gênero não é compatível com a dignidade e o valor do ser humano e deve, sobretudo, ser eliminada (através de medidas legais, da ação nacional e da cooperação internacional nos campos do desenvolvimento econômico e social, educacional, da saúde e maternidade segura e do apoio social). ${ }^{38}$

Torna-se bastante válida a inclusão do dispositivo: Os direitos do homem, das mulheres e das crianças do sexo feminino constituem uma parte inalienável, integral e indivisível dos Direitos Humanos universais. A participação plena e igual das mulheres na vida política, civil, econômica, social e cultural, em nível nacional, regional e internacional, e a erradicação de todas as formas de discriminação com base no sexo constituem objetivos prioritários da comunidade internacional. ${ }^{39}$

Esses Instrumentos assinados por ocasião da II Conferência Mundial de Direitos Humanos enfatizam as responsabilidades de todos dos Estados, em conformidade com a Carta das Naçôes Unidas, de desenvolver e estimular o respeito dos Direitos Humanos e liberdades fundamentais de todas as pessoas sem distinção de raça, sexo, idioma ou religião. Neste contexto, os Direitos Humanos das mulheres e das meninas são inalienáveis e constituem parte integral e indivisível dos Direitos Humanos universais. A plena participação das mulheres, em condiçóes de igualdade, na vida política, civil, econômica, social e cultural nos níveis nacional, regional e internacional e a erradicação de todas as formas de discriminação, com base no sexo, são objetivos prioritários da comunidade internacional. De forma pioneira no Sistema Global de Direitos Humanos, colocou a ideia de que a violência contra as mulheres e meninas constitui uma violação aos Direitos Humanos. ${ }^{40}$

A Declaração e Plataforma de Ação da Conferência Internacional sobre População e Desenvolvimento - Cairo, 1994, constitui outro válido texto normativo que merece destaque. A política adotada na Conferência do Cairo representa uma importante modificação na esfera de população e desenvolvimento, efetiva a ideia de direitos reprodutivos e, dessa maneira,

37 Instituto de Bioética, Direitos Humanos e Gênero e Associação Lésbica Feminista de Brasília Coturno de Vênus. Legislação e Jurisprudência LGBTTT. Brasília. Brasil, 2007, p. 52.

38 ISIS. Instrumentos Internacionais e Regionais para combater a violência contra a mulher. Disponível em: <http:// www.isis.cl/temas/vi/activismo/Portugues/07INSTRUM-PORT.pdf>. Acesso em: 06 jan. 2022.

39 OBSERVATÓRIO DE GÊNERO. Principais Documentos Internacionais para a Promoção dos Direitos das Mulheres e da Igualdade de Gênero. Disponivel em: <http://www.observatoriodegenero.gov.br/eixo/internacional/ documentos-internacionais $>$. Acesso em: 06 jan. 2022.

40 UNHCHR. Conferência Mundial de Direitos Humanos, Viena 1993. Disponível em: <http://www.unhchr.ch/ huridocda/huridoca.nsf/(Symbol)/A.CONF.157.23.Sp?OpenDocument>. Acesso em: 06 jan. 2022. 
direciona a base da regulação da fecundidade, antes pertencente ao controle populacional, para a abrangência dos direitos individuais das pessoas. Foram através da Declaração e Plataforma do Cairo que se reconheceu que a eliminação de todas as formas de violência contra a mulher, assim como o aumento da igualdade de gênero, do poder feminino, inclusive, no que diz respeito à capacidade de controlar as decisóes sobre sexualidade e reprodução. Esses preceitos constituem peças-chave nos programas de população e desenvolvimento. Adicionalmente, exorta os países a adotar medidas exaustivas para a eliminaçâo de todas as formas de violência contra as mulheres, adolescentes e meninas. ${ }^{41}$ É válido ressaltar que a presente Declaração possui um plano de ação (aera de população e desenvolvimento) estipulado para um objetivo de vinte anos, contados a partir da consolidação da referida Declaração. O princípio nove desse Programa determina a existência de várias formas de família, senão vejamos: A família é a unidade básica da sociedade e, portanto, deve ser fortalecida. Tem o direito de receber proteção compreensiva e apoio. Em sistemas culturais, políticos e sociais distintos existem várias formas de família. Deve-se aceder ao casamento através da livre vontade dos futuros esposos, devendo marido e mulher ser parceiros iguais. ${ }^{42}$

Segue o presente trabalho com a evidenciação dos textos da Declaração e Plataforma de Ação da IV Conferência Mundial da Mulher - Beijing, 1995 (Firmada pelo Brasil em 24 de janeiro de 1992) ${ }^{43}$. Dentre os diversos assuntos presentes na Conferência dessa cidade chinesa, se evidenciaram as manifestaçóes internacionais de combate à violência (uma das principais causas impeditivas do objetivo de igualdade, desenvolvimento e paz, além de violar, atrapalhar e impedir o proveito dos Direitos Humanos e das liberdades fundamentais. Nesse sentido, se estabeleceram medidas recomendáveis para a prevenção, proteção e reparação às vítimas, além de educação, eliminação de práticas preconceituosas (ideários de superioridade e inferioridade de sexo), reabilitação dos agressores e muitas outras. ${ }^{44}$

Preceitos de Direitos sexuais como Direitos Humanos também são encontrados na Declaração do Milênio das Naçôes Unidas - Cúpula do Milênio de 2000. Para que se efetive o que foi celebrado durante a Cúpula do Milênio se torne realidade, até 2015 os países devem adotar os seguintes Objetivos de Desenvolvimento do Milênio (ODM): 1- Erradicar a extrema pobreza e a fome; 2- Atingir o ensino básico universal; 3-Promover a igualdade entre os sexos e a autonomia das mulheres; 4-Reduzir a mortalidade infantil; 5-Melhorar a saúde materna; 6.

41 ISIS. Instrumentos Internacionais e Regionais para combater a violência contra a mulher. Disponível em: <http:// www.isis.cl/temas/vi/activismo/Portugues/07INSTRUM-PORT.pdf>. Acesso em: 06 jan. 2022.

42 DHNET. A Conferência do Cairo sobre População. Disponível em: <http://www.dhnet.org.br/direitos/militantes/ lindgrenalves/alves.htm>. Acesso em: 06 jan. 2022. Este Princípio foi muito polemizado e, vários países, apresentaram reservas com relação às expressóes referentes à familia e apresentaram declarações taxativas quanto sua ampliação fora do contexto homem $X$ mulher, como exemplificamos com o caso de Honduras: “... declaramos também que os termos "composiçấo e estrutura da família", "tipos de famílias", "diferentes tipos de famílias", "outras uniōes" e expressöes semelhantes só podem ser aceitos no entendimento de que, em Honduras, esses termos nunca poderão significar unióes de pessoas do mesmo sexo". Instituto de Bioética, Direitos Humanos e Gênero e Associação Lésbica Feminista de Brasília Coturno de Vênus. Legislação e Jurisprudência LGBTTT. Brasília. Brasil, 2007, p. 53.

43 A Plataforma para a Ação de Beijing identifica na violência contra a mulher um obstáculo para o sucesso dos objetivos de igualdade, desenvolvimento e paz, bem como um ato que viola e impóe obstáculos ao usufruto dos direitos humanos e liberdades das mulheres. A violência contra a mulher foi incluída como uma das doze "áreas críticas", às quais a ação dos governos, da comunidade internacional e da sociedade civil, incluindo as organizaçôes não-governamentais e o setor privado, devem se dirigir com o fim de alcançar a igualdade de gênero e o avanço da mulher. ISIS. Instrumentos Internacionais e Regionais para combater a violência contra a mulher. Disponível em: <http://www.isis.cl/temas/vi/activismo/Portugues/07INSTRUM-PORT.pdf>. Acesso em: 06 jan. 2022.

44 Instituto de Bioética, Direitos Humanos e Gênero e Associação Lésbica Feminista de Brasília Coturno de Vênus. Legislação e Jurisprudência LGBTTT. Brasília, Brasil, 2007, p. 54. 
Combater o HIV/Aids, a malária e outras doenças; 7-Garantir a sustentabilidade ambiental; 8-Estabelecer uma parceria mundial para o desenvolvimento. ${ }^{45}$

Em nesse aspecto de direitos sexuais como direitos humanos também se depara com a Declaração e Programa de Ação da III Conferência Mundial contra o Racismo, Discriminação Racial, Xenofobia e Intolerância Correlata - Durban, África do Sul, 2001. Esses Textos foram inspirados na luta heroica do povo da África do Sul contra o sistema institucionalizado do "Apartheid", bem como na luta por igualdade e justiça em um clima de democracia, desenvolvimento, Estado de direito e respeito aos Direitos Humanos, reafirmou-se os princípios de igualdade e não-discriminação reconhecidos na Declaração Universal de Direitos Humanos e incentivando o respeito aos Direitos Humanos e às liberdades fundamentais para todos, sem distinção de qualquer tipo, seja de raça, cor, sexo, língua, religião, opinião política ou qualquer outro tipo de opiniáo, origem social e nacional, propriedade, nascimento ou outro status. ${ }^{46}$

Com base nessas opinióes, a Espanha também assumiu essas diretrizes e o próprio Poder Legislativo inovou no sentido de criar normas legais que regulassem a matéria de gênero buscando instrumentos que permitissem a integração cidadã e a igualdade de trato entre homens e mulheres (Art.: 23 "a educação para a igualdade de mulheres e homens". Art. 24 "Integração do princípio da igualdade na política de educação". Lei Orgânica para a igualdade efetiva entre mulheres e homens, políticas de inclusão do gênero humano e, também, relacionadas aos temas das liberdades sexuais, proteção à violência de gênero (Lei Orgânica 1/2004- medidas de proteção integral contra à violência de gênero. Lei que trata das medidas de proteção) e etc. Segundo Alícia Muñoz: España, haciéndose eco de las demandas del feminismo, y respondiendo a las recomendaciones y compromisos internacionales, ha desarrollado diversas politicas de igualdad. De acordo com esse seguimento, a autora desenvolve suas aportaçóes relacionando com um dos oito Objetivos do Desenvolvimento do Milênio das Naçôes Unidas - Eliminar a disparidade de gênero (educação primária e secundária, preferentemente para 2005 e, em todos os níveis educativos no ano de 2015. Cita-se, mais especificamente o Marco de Dakar - Senegal 2000, com o objetivo de lograr uma educação para todos. No marco espanhol, usa-se a Lei Orgânica de Educação de 3 de maio de 2006 - Educação para a cidadania, como por exemplo: prestar especial atención a la incorporación real de los Derechos de las Mujeres, a través de la enseñanza de la igualdad entre éstas y los hombres. Mas é válido lembrar que estes incentivos e políticas de integração e desenvolvimento educativo vêm sofrendo variados problemas de lograr seus principais objetivos, basicamente devido a valores religiosos, principalmente pertencentes às ideologias da Igreja Católica ou partidários de partidos políticos conservadores, que inviabilizam os objetivos de conseguir um trato igualitário e uma conscientização inclusiva e participativa real da sociedade espanhola, como argumento pela não aceitação da educação para a cidadania. ${ }^{47}$

A igualdade de trato entre homens e mulheres, assim como a inclusão de grupos vitimados se torna mais difícil. Por esta razão, as políticas de educação são importantes para mudanças de realidades. É viável ressaltar que essas ideias de respeito de direitos, assim como

45 Instituto de Bioética, Direitos Humanos e Gênero e Associação Lésbica Feminista de Brasília Coturno de Vênus. Legislação e Jurisprudência LGBTTT. Brasília, Brasil, 2007, p. 54.

46 Instituto de Bioética, Direitos Humanos e Gênero e Associação Lésbica Feminista de Brasília Coturno de Vênus. Legislação e Jurisprudência LGBTTT. Brasília, Brasil, 2007, p. 55.

47 VERBICARO SOARES, Douglas. Las mujeres y las personas homosexuales en las Fuerzas Armadas. Especial referencia a las FF.AA. brasileñas. Trabajo fin de curso Máster Oficial en Estudios Interdisciplinares de Género. Universidad de Salamanca. Salamanca, Espanha, 2012, p. 38. 
outros textos internacionais, todos aceitos inicialmente em reunióes celebradas pelo mundo, em realidade, parecem náo usadas quando se necessita efetivar a aplicaçáo de um direito, pois em muitos lugares, as mais variadas violaçóes a esses preceitos seguem sendo cometidas. A criação de mecanismos de proteçáo que visem o respeito de direitos é indispensável para o ideal de igualdade de tratamento entre as pessoas em toda a sua amplitude e sua efetividade depende que esses textos normativos possam estar adequados às realidades econômicas, políticas e, sobretudo, sociais, exigidas e objetivas em sociedade, seja em um país ou num contexto globalizado. Esse conceito deve ser levado em conta, justamente para que um direito não caia em desuso ou pior, que seja considerado por seus seguidores como injustos ou pouco eficazes. ${ }^{48} \mathrm{Com}$ posicionamento semelhante planteia Alícia Muño: llegar a un entendimiento entre todas las fuerzas politicas, educativas, culturales y mediáticas para difundir una educación formal e informal que contribuya a potenciar una plena igualdad entre mujeres y hombres, eliminado los prejuicios ligados al género. ${ }^{49}$

Com base nas ideias expostas anteriormente, pode-se chegar ao entendimento de que existe um número significativo de normas que tratam sobre a proteção dos direitos sexuais e, em consequência, dos Direitos Humanos. Normas essas que estão relacionadas ao combate às diferentes atitudes que violem a igualdade de trato e a liberdade de cada pessoa quanto a seus direitos mais íntimos. Embora, muitas dessas normas ainda possuem muitas lacunas, fato que impossibilita a sua concreta efetivação e integração com as realidades sociais, econômicas, políticas existentes no mundo, pois em realidade, os preceitos previstos nos distintos textos normativos existentes, parecem não viabilizar o respeito às essências de seus conteúdos explícitos e ratificados pelos países. Nesse sentido, sábias são as palavras de José Claudio Monteiro de Brito Filho que ao retratar a existência de diversas normas, aduz que: a não eficácia dos textos nacionais e internacionais se consolida pela discriminação vedada em apenas algumas de suas formas, bem como não são todos os grupos excluídos que gozam de proteção, nem em todo o território nacional brasileiro, fato esse que se estende de maneira análoga a outros países pelo mundo, em diversas sociedades. ${ }^{50}$

Se por um lado a existência de diversos Textos Normativos que tratam de preceituar os direitos sexuais e os Direitos Humanos em seu reconhecimento internacional e a falta de efetividade dos mesmos para a real proteção desses direitos aumenta a problemática exposta. Por outro lado, indica-se como mecanismo de efetivação e viabilização de direitos o mecanismo da educação como ajudante na conscientização humana.

Segundo Félix López Sánchez, existe a necessidade de se reforçar nas sociedades humanas:

As duas identidades, de varão e de mulher, como um fato de diversidade que nos enriquece, de forma que garotos e garotas estejam satisfeitos com sua identidade, deve ir unido à análise da importância social dos róis, a crítica de toda forma de discriminação por sexo e o reconhecimento do direito a se expressar como cada um considere mais oportuno. ${ }^{51}$

Seguindo o raciocínio do autor, ressalta-se a validez de se defender a diversidade náo discriminatória em todas as suas maneiras de expressão, contra qualquer atitude que ameace

48 Instituto de Bioética, Direitos Humanos e Gênero e Associação Lésbica Feminista de Brasília Coturno de Vênus. Legislação e Jurisprudência LGBTTT. Brasília. Brasil, 2007, p. 55-6.

49 VERBICARO SOARES, Douglas. Las mujeres y las personas homosexuales en las Fuerzas Armadas. Especial referencia a las FF.AA. brasileñas. Trabajo fin de curso Máster Oficial en Estudios Interdisciplinares de Género. Universidad de Salamanca. Salamanca, Espanha, 2012, p. 39.

50 BRITO FILHO. José Claudio Monteiro. Direitos Fundamentais \& Relaçóes Sociais no Mundo Contemporâneo. Direitos Humanos e Discriminação no Brasil. Editora Juruá. Curitiba/Brasil, 2005, p. 225.

51 SÁNCHEZ, Félix López. La Educación Sexual. Biblioteca Nueva. Madrid, Espanha, 2005, p. 144. 
a liberdade e respeito à diversidade. Deve-se combater o sexismo. Parece educativamente mais acertado deixar que varôes e mulheres, cada pessoa, possa se expressar da forma que deseje, através da liberdade de gestos, emoçôes, atitudes pessoais ou não, vestimentas, jogos, profissões etc. A discriminação entre os sexos é condenável e a criação de iniciativas para se conseguir a igualdade de trato entre homens e mulheres é de fundamental importância. ${ }^{52}$

\section{Consideraçóes finais}

De esta maneira se notou que o tema sobre violência de gênero é atual e se encontra nas bases do ideal feminista de igualdade de trato e luta contra os sistemas paternalistas de repressão, violência e submissão. Na Espanha, o Poder Legislativo já desenvolveu mecanismos de proteção dos coletivos vitimados devido ao gênero, também criou cotas de igualdade e ratificou variados instrumentos normativos internacionais sobre estas questôes. Neste sentido podemos utilizar as idéias, por analogia, de Norberto Bobbio sobre o presente e o futuro dos Direitos Humanos: ${ }^{53}$ Apesar das antecipaçôes iluminadas dos filósofos, das corajosas formulaçóes dos juristas, dos esforços dos politicos de boa vontade, o caminho a seguir é ainda largo para se chegar a se efetivar os direitos humanos (homens e mulheres). Dizia Bobbio que a questão já não seria de proclamar novos direitos ou idealmente reconhecer-los e sim proteger-los, mesmo que se tenha que ser utilizado contra o próprio Estado que o viole. Assim, ao final se logrará um real cambio dos direitos dos cidadãos positivados nos direitos dos homens.

Por este motivo, se entende que a educação é fundamental para conscientizar e cambiar as realidades de violência de gênero na sociedade espanhola, assim como por outras sociedades internacionais, pois quando se naturalize o valor positivo que se tem de ser mulher, e se logre uma instrução baseada em valores de igualdade (combate aos estereótipos de gênero e mitos nas relaçôes de casais (familiares), reforçando os róis de homens e mulheres no trato igualitário entre os sexos, proporcionando nos gêneros os aspectos positivos, considerados tradicionalmente apenas para um gênero (ética do cuidado, afetividade e etc.). Estas são apenas algumas sugestôes para se buscar um verdadeiro cambio social sobre este tema estudado.

\section{Referências}

AMNESTY INTERNATIONAL (EDAI). Los derechos humanos, un derecho de la mujer. Editorial Amnesty International. Madri, Espanha, 1995.

BOBBIO, Norberto. A Era dos Direitos. Ed. Campus. 17a Tiragem. Rio de Janeiro, Brasil, 1992.

BRITO FILHO. José Claudio Monteiro. Direitos Fundamentais \& Relaçóes Sociais no Mundo Contemporâneo. Direitos Humanos e Discriminação no Brasil. Editora Juruá. Curitiba, Brasil, 2005.

CONTRA LOS MALOS TRATOS. Reportaje violencia de género. Tribuna Universitaria. Salamanca no 507. 24-30 Noviembre 2008. 
DHNET. A Conferência do Cairo sobre População. Disponível em: <http://www.dhnet.org.br/ direitos/militantes/lindgrenalves/alves.htm>. Acesso em: 06 jan. 2022.

JUNQUEIRA, Rogério Diniz. Diversidade Sexual na Educação: problematizaçóes sobre a homofobia nas escolas. Coleção Educaçâo para todos. Brasília, Brasil, 2009.

Instituto de Bioética, Direitos Humanos e Gênero e Associação Lésbica Feminista de Brasília Coturno de Vênus. Legislação e Jurisprudência LGBTTT. Brasília, Brasil, 2007.

IPPF (International Planned Parenthood Federation): Charter of sexual and reproductive rights. Disponivel em: <http://www.ippf.org/en/Resources/Statements/

$\mathrm{IPPF}+$ Charter+on+Sexual+and+Reproductive+Rights.htm>. Acesso em: 06 jan. 2022.

ISIS. Instrumentos Internacionais e Regionais para combater a violência contra a mulher. Disponível em: <http://www.isis.cl/temas/vi/activismo/Portugues/07INSTRUM-PORT.pdf>. Acesso em: 06 jan. 2022.

MANUAL DE COMUNICAÇAO LGBT. Lésbicas, Gays, Bissexuais, Travestis e Transexuais. Brasília. Brasil, 2010.

OBSERVATÓRIO DE GÊNERO. Principais Documentos Internacionais para a Promoção dos Direitos das Mulheres e da Igualdade de Gênero. Disponível em: <http://www. observatoriodegenero.gov. br/eixo/internacionalldocumentos-internacionais $>$. Acesso em: 06 jan. 2022.

OLIVEIRA, Almir. Curso de Direitos Humanos. Rio de Janeiro. Brasil: Ed. Forense, 2000.

PGE. Pacto Internacional dos Direitos Econômicos, Sociais e Culturais de 1966. Disponível em: <http://www.pge.sp.gov.br/centrodeestudos/bibliotecavirtual/instrumentos/direitos.htm>. Acesso em: 06 jan. 2022.

PRECIADO, Beatriz. Manifiesto Contrasexual. Colección Argumentos. Barcelona. Espanha: Editorial Anagrama, 2011.

ROLIM. Pacto Internacional dos Direitos Civis e Politicos (1966). Disponível em: <http://www. rolim.com.br/2002/_pdfs/067.pdf>. Acesso em: 06 jan. 2022.

SÁNCHEZ, Félix López. La Educación Sexual. Biblioteca Nueva. Madrid, Espanha, 2005.

SEAGER, Joni. ATLAS Akal. Del Estado de la Mujer en el Mundo, 1997.

SEGARRA Marta y CARABÍ Àngels. Nuevas Masculinidades. Construyendo nuevas masculinidades: Una introducción. Icaria, mujeres y culturas. Barcelona, Espanha, 2000.

TELO, María. Ponencia oferecida no Instituto Cervantes dia 23 de novembro de 2005. Disponível em: <http://www.laotrapagina.com/articulo-168.html>. Acesso em: 06 jan. 2022.

UNHCHR. Conferência Mundial de Direitos Humanos, Viena 1993. Disponível em: <http:// www.unhchr.ch/huridocda/huridoca.nsf/(Symbol)/A.CONF.157.23.Sp?OpenDocument>. Acesso em: 06 jan. 2022.

VERBICARO SOARES, Douglas. Las mujeres y las personas homosexuales en las Fuerzas Armadas. Especial referencia a las FF.AA. brasileñas. Trabajo fin de curso Máster Oficial en 
Estudios Interdisciplinares de Género. Universidad de Salamanca. Salamanca, Espanha, 2012.

VIOLENCIA MULHER. CEDAW-Convenção sobre a Eliminação de Todas as Formas de Discriminaçâo contra a Mulher (1979). Disponível em: <http://www.violenciamulher.org. $\mathrm{br} /$ index.php?option=com_content $\& v i$ wew $=$ article $\& i d=1229$ :cedaw-convencao-sobre-aeliminacao-de-todas-as-formas-de-discriminacao-contra-a-mulher-1979\&catid $=5$ : convencoese-outros-documentos-internacionais\&Itemid=10.htm>. Acesso em: 06 jan. 2022. 